\title{
APRENDIZAGEM NARRATIVA E CURRÍCULO: OLHARES PLURAIS
}

\section{GOODSON, Ivor F. Currículo, narrativa pessoal e futuro social. Tradutor: Henrique Carvalho Calado; revisão da tradução: Maria Inês Petrucci-Rosa e José Pereira de Queiroz. Campinas, SP: Editora da Unicamp, 2019.}

\author{
(1D)Joelson de Sousa Morais \\ Doutorando em Educação (Bolsista CAPES), \\ Universidade Estadual de Campinas - UNICAMP. \\ Campinas, SP - Brasil. \\ joelsonmorais@hotmail.com
}

\section{Para citar- (ABNT NBR 6023:2018)}

MORAIS, Joelson de Sousa. Aprendizagem narrativa e currículo: olhares plurais. Resenha. Eccos Revista Cientifica, São Paulo, n. 56, p. 1-6, e18594, jan./mar., 2021. Resenha da obra de GOODSON, Ivor F. Currículo, narrativa pessoal e futuro social. Tradutor: Henrique Carvalho Calado; revisão da tradução: Maria Inês Petrucci-Rosa e José Pereira de Queiroz. Campinas, SP: Editora da Unicamp, 2019. https://doi.org/10.5585/eccos.n56.18594.

Ivor F. Goodson trabalha na Guerrand-Hermès Foudation for Peace em Brighton -

U.K. Desenvolve pesquisas e estudos, há cerca de 40 anos, sobre questões cruciais do campo da Educação, políticas educacionais, estudos históricos das disciplinas escolares, teorias narrativas, história de vida, profissionalismo e carreira docente (www.ivorgoodson.com). Já trabalhou em instituições de pesquisa educacional em vários países, como EUA, Canadá, Estônia e Inglaterra.

Lançado pela editora da Unicamp, traduzido do inglês para o português aos cuidados de Henrique Carvalho Calado e com revisão da tradução feita por Maria Inês Petrucci-Rosa e José Pereira de Queiroz, o livro apresenta uma linguagem de fácil compreensão e apreensão pelo leitor, trazendo discussões que se aproximam da realidade brasileira quanto ao currículo, à narrativa sistêmica e às narrativas das histórias de vida em contextos de desenvolvimento profissional de professores e outros profissionais.

A obra Currículo, narrativa pessoal e futuro social (2019) traz uma perspectiva que dá legitimidade à voz do professor e a de outros sujeitos em contextos de desenvolvimento profissional, como dimensão constitutiva na construção de conhecimentos, no sentido de que suas histórias de vida possibilitam uma profícua forma de construção de um currículo 
narrativo como novo futuro social, representando potencialidades através das micropolíticas cotidianas que levam a mudanças plausíveis no desenvolvimento pessoal e profissional.

Constituído de 295 páginas, dividido em três partes e composto por dez capítulos, o livro, entre outras discussões, contempla: os processos e tempos de mudança educacional com foco no currículo; a ascensão da narrativa de vida e o currículo como narrativa; o conhecimento profissional e as histórias de vida dos professores; o pesquisador educacional como intelectual público e, de modo mais específico, o que focaliza as ideias da obra, o conhecimento, a narrativa pessoal e o futuro social, com a defesa da aprendizagem narrativa em contraponto ao currículo como prescrição nas mudanças curriculares e no campo da aprendizagem docente e das questões atinentes ao currículo como um todo.

Com abordagens conceituais, históricas, políticas e com críticas ao conhecimento e aos estudos curriculares, o autor vai tecendo um esboço dos processos de escolarização que, ao longo do tempo, foram sofrendo mutações, avanços e recuos quanto à legitimidade de determinados programas de governo e disciplinas no campo educacional em países emergentes.

O fato de tecer críticas de que "[...] o que acontece no nível das políticas é visto como algo que tem pouco ou nada a ver com as reais necessidades da escola" (GOODSON, 2019, p. 85) tem manifestado modos de resistências ou possibilidades de refração pelo currículo por parte de muitos professores e educadores que têm se defrontado com imposições em seus territórios, trazendo afetações que emergiam nas histórias narrativas que Goodson desvelou em processos de pesquisa e que, há mais de quatro décadas, vem tornando-se fontes de seus estudos.

Assim, no livro, são tecidas discussões que clarificam as transformações que historicamente foram sendo impulsionadas pelas determinações do Estado $\mathrm{e}$ as especificidades das questões educacionais tramadas no contexto curricular, que se perfilaram em alguns territórios de várias partes do mundo, dentro os quais o Reino Unido, os Estados Unidos e, mais precisamente, a Inglaterra, onde reside o autor, entre outros lugares, retratados de modo secundário.

Historicamente, os aspectos pelos quais eram designados e direcionados os estudos curriculares - diferentes estratificações sociais, faixa etária dos sujeitos e aspectos econômicos, políticos e culturais - determinavam, em muito, o crivo identificador e de diferenciação social das pessoas, razão pela qual estes dois elementos estabeleceram um lugar decisivo na epistemologia da escolarização. 
O legado da história do currículo é, pois, uma das tematizações tecidas no livro, que é entrelaçado ao processo de formação e desenvolvimento profissional dos professores, em face da supremacia do poder político e das reverberações que isso causa nos aspectos pessoais e no trabalho docente, que ganha visibilidade nas histórias narrativas destes profissionais da educação.

Um dos fortes componentes do currículo caracterizado como conflituoso - que situa, de um lado, as perspectivas e práticas curriculares dos professores concebidas por eles a partir de seus contextos reais e, do outro, a imposição curricular pela ideologia dominante (que destitui as possibilidades criativas e criadoras do professor legitimar as experiências plausíveis que considera pertinente no aprender e ensinar cotidiano) - pode ser retratado com a seguinte citação do autor:

O conflito e os acordos ao redor do currículo escolar, e dentro das disciplinas escolares, representam, ao mesmo tempo, uma fragmentação e uma internalização das dificuldades acerca da escolarização. Fragmentação, porque os conflitos se sucedem agora em um conjunto de disciplinas compartimentadas; internalização, porque ocorrem dentro dos limites das escolas e das disciplinas (GOODSON, 2019, p. 60-61).

Portanto, a ideia e a prática de currículo que vêm consolidando-se e se alicerçando no cenário educacional tratam de uma dimensão que se corporifica através de lutas e embates entre "aqueles que ensinam", no caso dos professores, e "aqueles que ditam as regras do jogo", no caso dos poderes políticos hegemônicos do Estado.

Situando essas duas esferas sociais - Estado e escola -, vale ressaltar que a hegemonia dominante busca implementar reformas educativas com base nos seus ideais, nos princípios mercadológicos e forjadas no âmbito do capital, o que nem sempre atende as necessidades daqueles que habitam as escolas nem representam seu mundo.

O pensador inglês declara que "[...] de fato, estamos entrando em um período de tipos particulares de narrativa: narrativas de vida e narrativas em pequena escala" (GOODSON, 2019, p. 120). Prova disso é que, por meio do mundo micro e pessoal, é possível apreender uma realidade macroscópica e que retrata as diferentes questões pulsantes do meio circundante, já que, no século XX, testemunhamos, na visão do autor, o colapso das grandes narrativas por não conseguir captar o potencial de implicações e reflexões que pudessem ser concebidas em dimensões preponderantes para a compreensão da vida e de transformações substanciais nos planos econômico, político, social e cultural.

A forma como o conhecimento vem estruturando-se e sendo organizado no desenvolvimento da educação e da sociedade tem uma perspectiva alicerçada no poder 
hegemônico, que vai delimitando o que deve ser ensinado em lugar do que não deve bem como quais sujeitos podem aprender "o quê", em quais contextos, circunstâncias e de quais classes sociais pertencem. Isso pode ser atestado porque

[...] as disciplinas escolares são definidas não de maneira desinteressada e escolástica, mas sim em uma relação próxima com o poder e os interesses de grupos sociais. Quanto mais poderoso o grupo social, mais ele é capaz de exercer poder sobre o conhecimento escolar (GOODSON, 2019, p. 97).

Daí o poder de classificar e criar determinados aspectos no âmbito do conhecimento que situam os que são "mais capazes" dos "menos capazes", gerando desigualdades e contribuindo para reforçar as disparidades socioeconômicas, políticas e culturais de um povo que vem ampliando-se ao longo do tempo na história da educação e na humanidade.

Goodson toca em assuntos caros e sensíveis à educação, particularmente quando trata do processo de transição entre a formação inicial e os primeiros anos no exercício da docência. Os professores iniciantes passam, portanto, a se afirmar na profissão tendo, muitas vezes, que se defrontar com inúmeros desafios e incertezas sobre a prática, configurando-se as dimensões da constituição de suas identidades e a inserção/socialização profissional como lugar de pertencimento que os preocupam. Assim, o fato de ouvir suas vozes é uma maneira outra potente e fundamental para a elaboração de bons modelos de desenvolvimento profissional na carreira docente.

As histórias narrativas de vida representam um dispositivo metodológico em que os professores revelam os contextos micropolíticos de suas experiências e itinerários formativos, em que o lado pessoal constitui um teor fortemente implicado de reflexões e gera inúmeras outras questões em um plano mais amplo, situando os aspectos políticos, pedagógicos e sociais dos quais fazem parte e atravessam o seu cotidiano e sua subjetividade.

Há, na concepção do pensador britânico, uma articulação implicada entre os aspectos históricos, políticos e sociais e os modos como a narrativa se configura no campo da experiência de professores e outros profissionais que estão no âmbito de sua pesquisa. Para o autor, entretecidas pelas questões curriculares estão as práticas exercidas por eles e as possibilidades de refração com as quais se defrontam. Assim, as narrativas que emergem dos sujeitos e as histórias que muitas vezes são constituídas de sentidos, valores e crenças representam uma potencialidade formativa, de transformação e emancipação, pois partem do sentido e da vida que tem cada um para uma dimensão mais ampla, envolvendo os contextos políticos, econômicos, culturais e sociais. 
As fontes narrativas se configuram, então, como um dispositivo de pertinência porque dá legitimidade às profícuas experiências e aos conhecimentos que emergem do próprio cotidiano do sujeito e de si próprio. Tanto é relevante, que o autor declara:

[...] Narrativas propiciam e criam espaço para "momentos pedagógicos" nos quais as pessoas podem se conectar consigo mesmas, umas com as outras, com suas próprias cultura e tradição, com suas esperanças e aspirações e, em última instância, como uma construção de conhecimento intencional e orientada, que serve a suas trajetórias pessoais e públicas (GOODSON, 2019, p. 114).

A narrativa, portanto, é o modo privilegiado de emergir os contextos de vida do sujeito e que se tece em meio aos inúmeros aspectos da vida cotidiana pelos quais estão sendo construídas suas concepções, experiências, reflexões e saberes de várias dimensões no plano da subjetividade e, por isso, emerge uma potencialidade formadora e reflexiva capaz de gerar transformações acerca de si, da formação e da experiência profissional.

O livro apresenta um conjunto de histórias narrativas de vidas de professores, enfermeiros e outros profissionais distribuídas em alguns capítulos, os quais são evocações em situação de aprendizagem da profissão e em múltiplos outros contextos em que se situam nas relações com o trabalho, com as políticas e reformas curriculares, com outros profissionais e seus pares no cotidiano de suas realidades. Narrativas e histórias essas que refletem e refratam as políticas, os currículos e os modos de se constituir como pessoa e profissional, além de tantas outras conexões em que os sujeitos conseguem se entrelaçar aos grupos que participam em sua vida e profissão. Afinal de contas, “[...] o modo como os professores constroem as suas realidades profissionais e a forma como levam as suas vidas nas salas de aula são um contínuo processo de interpretação pessoal e contextual" (GOODSON, 2019, p. 148) que, muitas vezes, são evocados em suas narrativas, refletindo esses aspectos.

Ideias como o caráter excludente de algumas disciplinas escolares em prol de outras que promovem a inclusão, a justiça social e o aprendizado na perspectiva da ascensão e mobilidade dos sujeitos das classes populares são refletidas no livro, trazendo, de forma crítica, a centralidade do currículo como prescrição que ganha força pelas políticas exercidas no cenário britânico, apagando, assim, quaisquer possibilidades de construção de conhecimentos que levem em consideração os saberes e experiências de mundo dos professores em suas práticas cotidianas e dos alunos na formação e constituição de sua história de vida e acadêmica, conforme concebido no passado. Esse jeito de construir conhecimento se modificou ao longo do tempo, tanto que é apresentado, hoje, com disciplinas 
"dadas", "aceitas" e "tradicionais", sendo reforçadas, portanto, como dispositivos excludentes nas escolas e na formação dos sujeitos.

O currículo como narrativa, e que se centrou no que o intelectual inglês chama de currículo como aprendizagem narrativa, consiste "[...] na elaboração e manutenção continuada de uma narrativa de vida ou de identidade" (GOODSON, 2019, p. 282). Eis, portanto, o que defende Goodson (2019) em suas ideias já há mais de quatro décadas e reforçada neste livro. Nas pesquisas em que está envolvido, dentre as quais produzidas em parceria com o seu colega, o notável Andy Hargreaves, que o autor cita no livro, perfila-se a perspectiva de um estudo longitudinal de quatro anos que o autor vem desenvolvendo e que visa aprofundar entendimentos sobre o significado e a importância da aprendizagem informal na vida de adultos além de identificar formas de apoio e aprimoramento para a sua aprendizagem.

Enfim, o livro conclui propondo algumas premissas amparadas numa crítica do currículo escolar estandardizado. O autor defende uma perspectiva outra que potencialize os processos formativos e a aprendizagem profissional dos professores como instrumento de mudança legítima e crucial para um novo futuro social e, assim, reitera que “[...] a inércia contextual de um currículo prescritivo baseado em conteúdo não resistirá às rápidas transformações do mundo globalizado" (GOODSON, 2019, p. 286).

Portanto, para romper com esse modelo impositivo do currículo prescritivo, urge a necessidade de mudanças que deem visibilidade aos atores sociais que fazem da educação o cenário de micro mudanças, mas que não são consideradas, vistas e legitimadas pelo poder hegemônico, ou seja, “[...] no novo futuro social, devemos esperar que o currículo se envolva com as missões de vida, com as paixões e com os propósitos que as pessoas articulam em suas vidas. Esse seria, verdadeiramente, um currículo para o empoderamento" (GOODSON, 2019, p. 287).

Currículo, narrativa pessoal e futuro social é, pois, uma obra em que Ivor F. Goodson brilhantemente nos presenteou com potentes reflexões e contribuições para educadores, professores, pesquisadores e profissionais que se interessam e desenvolvem estudos e pesquisas no campo da formação de professores, currículo, aprendizagem profissional da docência, da abordagem narrativa (auto)biográfica e histórias de vida e de outros assuntos de valor inestimável e sensível no campo da formação humana e da educação como um todo. 